\title{
Effects of high intensity canoeing training on fibre area and fibre type in the latissimus dorsi muscle
}

\author{
S.J. Baker and L. Hardy
}

Physical Education Department, University College of North Wales

\begin{abstract}
A high intensity short duration exercise training programme was undertaken by nine subjects on three occasions each week for nine weeks. Muscle samples from the latissimus dorsi were taken by needle biopsy, at rest, before and after training. The results revealed that there was no change in either Type I or Type II muscle fibre distribution following training. Type I fibre area did not alter significantly as a result of the training stress. Mean cross-sectional area of Type II fibres was 82 per cent greater post-training than pre-training.
\end{abstract}

Keywords: Slalom canoeing, high intensity training, muscle fibre area, muscle fibre type

\section{Introduction}

The specificity of training was difficult to explain with respect to muscle function until evidence had accumulated, mainly from animal studies, describing the contractile properties of muscle fibres alongside their metabolic properties. Several researchers suggested that Type II muscle fibres were recruited as the force generated increased ${ }^{1-3}$. Later, Thorstensson and coworkers suggested that there was a positive correlation between the proportion of Type I fibres and dynamic muscle strength.

It has been shown that lactate produced during anaerobic glycolysis diffuses from the muscle and accumulates in the blood where it can serve as an indicator of the extent to which anaerobic processes are activated during exercise ${ }^{5}$. At equivalent absolute levels of oxygen uptake, blood lactate concentrations are greater during arm work than during leg work ${ }^{6}$. This may be explained by the notion that, for a given work load, as the muscle mass decreases the anaerobic contribution to the work output must increase.

In slalom canoeing, it has been shown that at world championship level competitors demonstrate a considerable anaerobic contribution to the total energy supply as manifested in post-competition lactate levels ${ }^{7,8}$. In the men's kayak event, the mean blood lactate concentration from five world class competitors

Address for correspondence: Dr S.J. Baker, National Coaching Centre, Ffriddoedd Building, University College of North Wales, Bangor, Gwynedd LL57 2DG'

(C) 1989 Butterworth \& Co (Publishers) Ltd

0306-3674/89/010023-04\$03.00 sampled at five minutes following the completion of their final run was $16.2 \mathrm{mmol} .1^{-1}$.

However, it is common for many competitors to concentrate their training, knowingly or otherwise, on anaerobic development ${ }^{9}$. This often takes the form of repetitive skill oriented 'gate practice' since the penalty for contacting a slalom gate during a competitive run is severe at international level. Although the importance of good 'gate' technique remains paramount to the slalomist, the physiological implications of incorporating more high intensity exercise during training may be important.

Electromyography studies have shown that during canoeing exercise a major protagonist muscle during the pulling phase of the stroke is the latissimus dorsi ${ }^{9}$. It has its origin on the crest of ilium, sacrum, lumbar vertebrae and the lower ribs and is inserted by a single flattened tendon into the anterior surface of the humerus. As the muscle twists in the region of the posterior axillary fold, it is easily palpated thus allowing a muscle sample to be taken safely using the needle biopsy technique without the risk of invading a deeper organ.

\section{Methods}

Nine fit adult male physical education students (age $21.5 \pm 2.5 \mathrm{yr}$, weight $71.0 \pm 5.3 \mathrm{~kg}$, height $177.8 \pm 5.0 \mathrm{~cm}$ [mean \pm sd]) who had a little experience of, but no specific training in kayak paddling, participated in the study.

Each subject attended the laboratory on three occasions each week for nine weeks to exercise with arms on an electronically controlled (LODE) canoeing ergometer. The 'paddling' action required to operate this equipment had been validated previously using cinematographical and electromyographical techniques?.

The exercise regimen is shown in Table 1. All subjects agreed to avoid additional forms of training and sporting exercise throughout the study. During the first week of training each subject established the maximal resistive force against which he could 'paddle' over a one minute period. Thus a pre-training performance value was recorded. At the midpoint of the study each subject was required to re-establish this value (Table 1$)$. 
Table 1. Progressive kayak training programme

\begin{tabular}{|c|c|c|c|c|c|}
\hline \multirow[b]{2}{*}{ Week } & \multicolumn{2}{|c|}{$\begin{array}{l}\text { Work Work load } \\
\text { IntervalPercent }\end{array}$} & \multirow{2}{*}{$\begin{array}{c}\begin{array}{c}\text { Intensity } \\
\text { Reus } \text { min }^{-1}\end{array} \\
\end{array}$} & \multirow{2}{*}{$\begin{array}{l}\text { Rest } \\
\text { mins }\end{array}$} & \multirow[b]{2}{*}{ Reps } \\
\hline & mins & $\max$ & & & \\
\hline 1 & \multicolumn{5}{|c|}{ Establish maximal work load for one minute duration } \\
\hline 2 & 3 & 40 & 40 & 1 & 10 \\
\hline 3 & 3 & 50 & 40 & 1 & 10 \\
\hline 4 & 3 & 55 & 40 & 2 & 10 \\
\hline 5 & 3 & 60 & 40 & 2 & 10 \\
\hline \multicolumn{6}{|c|}{ Re-establish maximal work load } \\
\hline 6 & 2 & 60 & 40 & 2 & 10 \\
\hline 7 & 1.5 & 80 & 40 & 3 & 10 \\
\hline 8 & 1 & 90 & 40 & 4 & 10 \\
\hline 9 & 1 & 100 & 40 & 4 & 10 \\
\hline
\end{tabular}

On the day prior to the start of the training programme, a muscle sample was obtained by needle biopsy from the latissimus dorsi of each subject ${ }^{10}$. A second sample from the same muscle was obtained by needle biopsy approximately 24 hours following completion of the training programme. It was hoped that this delay would allow any local effects of the last training bout to dissipate.

\section{Needle biopsy technique}

The subject assumed a prone position with the dominant arm abducted and supported by a pillow. An area of skin approximately $3 \mathrm{~cm}$ below the axillary fold was anaesthetized with $5 \mathrm{ml}$ of 1 per cent lignocaine hydrochloride. An incision approximately $2 \mathrm{~cm}$ long was made in the skin through which was introduced a UCH biopsy needle (model 3782) (Figure 1). Where the sample appeared to be small or inadequate, a second sample was taken through the same incision.

With the aid of a dissecting microscope, the sample was oriented with the fibres placed horizontally on a cover glass. The sample was transferred to a circular cork with the fibres in a plane at right angles to the surface of the cork, then mounted in embedding medium (OCT; Ames Tissue Tek). The cork and sample were immersed in isopentane cooled to the temperature of liquid nitrogen. Each sample was stored in liquid nitrogen overnight then transferred to a cryostat $\left(-20^{\circ} \mathrm{C}\right)$ where sections $(10 \mu \mathrm{m})$ were cut.

\section{Staining}

Sections were stained for myofibrillar ATPase activity at $\mathrm{pH} 9.5$ and with NADH-TR.

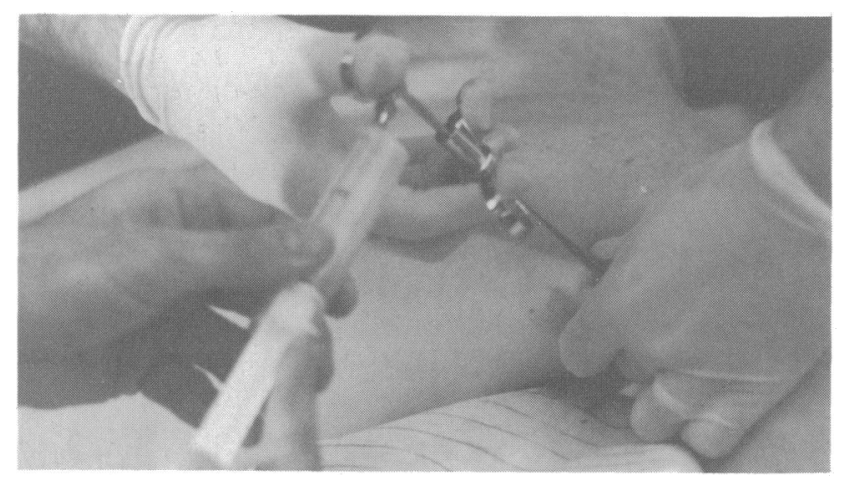

Figure 1. A biopsy needle with syringe attachment being introduced into the latissimus dorsi muscle of a prone subject

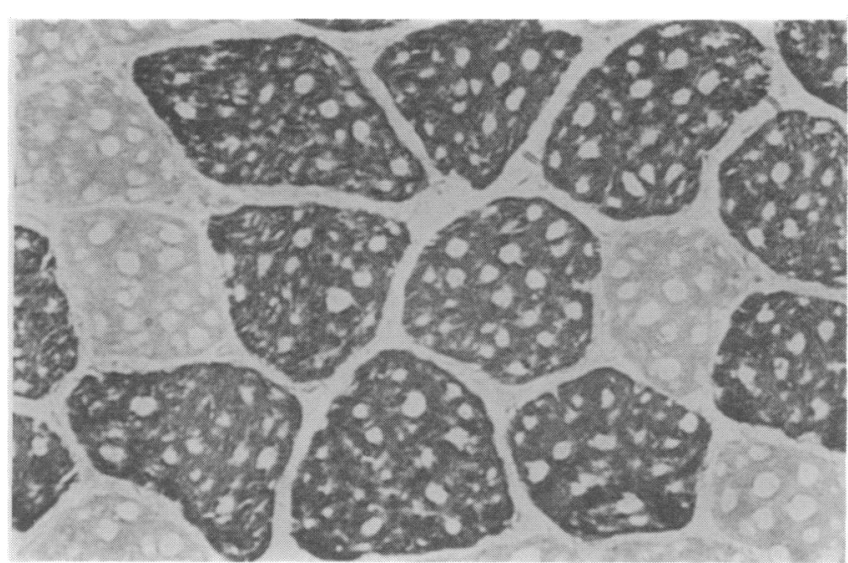

Figure 2. Section of human latissimus dorsi muscle showing dark Type I fibres and light Type II fibres. Staining was by ATPase at $\mathrm{pH} 4.6$

\section{Analysis of staining}

A Wild M5 microscope in conjunction with a Leitz Dialux microscope with a fibre optic light was used for fibre orientation and counting. Photomicrographs were taken with a Leitz Wetzler Orthoplan microscope. In each sample a total of 200 fibres were measured and classified. Pre- and post-training biopsy samples were analysed on different occasions. Fibre identification into Type I and Type II using mATPase stained sections was achieved by grid counting (Figure 2). Photomicrographs of serial sections stained for NADH-TR were used to calculate the mean fibre area to the nearest $10 \mu \mathrm{m}$, according to the method of the lesser diameter ${ }^{11}$.

\section{Results}

The results of muscle fibre typing from the pre- and post-training biopsies are shown in Table 2 . There was a mean difference in the proportion of Type I fibres pre- and post-training of 1.7 per cent and a 5.1 per cent difference in the proportion of Type II fibres. When examined more closely, the largest change in fibre distribution observed pre- and post-training is seen in subjects 6 and 8 who both recorded 13 per cent. This variation is within the limits suggested by Dubowitz and Brooke who reported the limits of variation that can be attributed to random fibre type distribution may approach 26 per cent ${ }^{11}$. The results are in general agreement with earlier reports that fibre distribution is not affected by training and is genetically determined ${ }^{12,13}$.

In addition to fibre typing, cross-sectional area was also measured pre- and post-training. These results are shown in Table 3. Four subjects (Ss 2, 4, 6, 8) showed an increase in cross-sectional area of Type I fibres following training, while the remaining five subjects showed a decrease. Only one subject (S 3) demonstrated a decrease in cross-sectional area of Type II fibres $\left(4265 \mu \mathrm{m}^{2}\right.$ cf $\left.3984 \mu \mathrm{m}^{2}\right)$. The remaining eight subjects showed large increases in Type II fibre areas post-training.

The change in cross-sectional area of fibre types, expressed as a ratio of the pre-training biopsy fibre area, are presented in Table 4. The largest increase in cross-sectional area in Type II fibres is seen in subject 
Table 2. Percentage fibre composition in latissimus dorsi preand post-training $(\mathrm{n}=9)$

\begin{tabular}{ccccc}
\hline & $\begin{array}{c}\text { TypeI\% } \\
\text { Pre- } \\
\text { training }\end{array}$ & $\begin{array}{c}\text { Post- } \\
\text { training }\end{array}$ & $\begin{array}{c}\text { Type II\% } \\
\text { training }\end{array}$ & $\begin{array}{c}\text { Post- } \\
\text { training }\end{array}$ \\
\hline $\mathrm{S}$ & & & & \\
1 & 57 & 54 & 43 & 46 \\
2 & 48 & 52 & 52 & 48 \\
3 & 58 & 53 & 42 & 47 \\
4 & 39 & 39 & 61 & 61 \\
5 & 49 & 47 & 51 & 53 \\
6 & 61 & 48 & 39 & 52 \\
7 & 39 & 37 & 61 & 63 \\
8 & 58 & 45 & 42 & 55 \\
9 & 49 & 52 & 51 & 48 \\
\hline $\mathrm{X}$ & 50.7 & 49.0 & 47.3 & 52.4 \\
$\mathrm{SD}$ & 8.4 & 8.4 & 6.6 & 6.7 \\
\hline
\end{tabular}

Table 3. Mean cross sectional areas $\left(\mu \mathrm{m}^{2}\right)$ of Type I and Type II fibres pre- and post-training $(n=9)$

\begin{tabular}{ccccc}
\hline & $\begin{array}{c}\text { Type Iarea }\left(\mu m^{2}\right) \\
\text { Pre- } \\
\text { training }\end{array}$ & $\begin{array}{c}\text { Post- } \\
\text { training }\end{array}$ & $\begin{array}{c}\text { Type II area }\left(\mu m^{2}\right) \\
\text { Praining }\end{array}$ & $\begin{array}{c}\text { Post- } \\
\text { training }\end{array}$ \\
\hline Sraining & & & & \\
1 & 2003 & 1919 & 2774 & 5151 \\
2 & 1573 & 2578 & 3678 & 6066 \\
3 & 2669 & 2408 & 4265 & 3984 \\
4 & 1763 & 1918 & 3837 & 4449 \\
5 & 2003 & 1817 & 2374 & 4895 \\
6 & 2209 & 2451 & 3965 & 3228 \\
7 & 2066 & 1452 & 2563 & 7614 \\
8 & 1596 & 2434 & 2001 & 4313 \\
9 & 1872 & 1758 & 2089 & 5047 \\
\hline $\bar{X}$ & 1984 & 2082 & 3057 & $4972^{*}$ \\
SD & 328 & 372 & 826 & 1200 \\
\hline
\end{tabular}

*Significantly different from pre-training $\mathrm{P}<0.05$

Table 4. The difference in fibre area measured at the post-training biopsy expressed as a percentage of the area measured at the pre-training biopsy for both fibre types

\begin{tabular}{ccc}
\hline & $\begin{array}{c}\text { Type Ifibres } \\
\% \text { change }\end{array}$ & $\begin{array}{c}\text { Type II fibres } \\
\% \text { change }\end{array}$ \\
\hline $\mathrm{S}$ & & \\
1 & -4 & 87 \\
2 & 64 & 65 \\
3 & -10 & -7 \\
4 & 9 & 16 \\
5 & -9 & 16 \\
6 & 6 & 19 \\
7 & -29 & 197 \\
8 & 52 & 116 \\
9 & -6 & 142 \\
\hline $\bar{X}$ & $8 \%$ & $82 \%$ \\
SD & 22 & 47 \\
\hline
\end{tabular}

7 (197 per cent). It is interesting to note that the Type I fibre area was also smaller after training in this subject (29 per cent). Student's t-test revealed no significant difference between Type I fibre area pre- and posttraining. However, there was a significant difference between Type II area pre- and post-training $(P>0.05)$.

\section{Discussion}

The findings from this investigation are particularly interesting to competitive slalom canoeists. In a previ- ous study reported from this laboratory, muscle samples from the medial deltoid of five international standard canoeists showed a high proportion of Type I fibres $(74 \pm 3.2 \text { per cent })^{14}$. These results were in broad agreement with those of Tesch and co-workers who also reported a high proportion of Type I fibres in the deltoid muscle of canoeists ${ }^{15}$. It has been shown previously that there is a significant correlation between a muscle's respiratory capacity and the onset of blood lactic acid accumulation ${ }^{16}$. The ability of an individual to utilize a high proportion of the maximal oxygen uptake at a reference blood lactate concentration can be viewed as a good indicator of aerobic fitness ${ }^{17}$.

The metabolic profile of Type II muscle fibres has been described by many researchers ${ }^{18-20}$ and favours ATP generation by glycolytic metabolism. Tesch and Karlsson have shown that subjects with a high percentage of Type II fibres demonstrate a higher blood lactate concentration at 50 per cent of maximal voluntary contraction (MVC) than at 75 per cent $\mathrm{MVC}^{15}$. During slalom competition, where it has been shown that at international level there is a considerable accumulation of lactate in blood, the intensity of isometric exercise while holding the paddle may be of importance ${ }^{7}$.

The increased Type II fibre area seen in this study suggest an increased number and/or size of myofibrils after training. This response may reflect greater Type II muscle fibre recruitment during kayaking. Factors which have not been investigated here, such as enzyme characteristics of muscle fibre types, would provide interesting information for the canoeists.

It has been suggested that the rate of lactic acid removal is directly proportional to the amount present $t^{21}$. More recently, Brooks and co-workers concluded that the fate of lactic acid following exercise appears to be oxidative $^{22}$. Koutedakis and Sharp demonstrated that following high intensity short term work, an active recovery period promotes blood lactate removal more than resting recovery ${ }^{23}$.

In canoeing, perhaps the characteristic repetitious paddling routines which many slalomists adopt in their training programmes not only improves slalom skill but also has a beneficial effect on aerobic development that would contribute to more rapid removal of lactate. It is suggested that perhaps if this type of interval training involves short maximal repetitions and short periods of recovery, it would produce increases in strength, speed and anaerobic capacity ${ }^{24}$.

This study investigated some of the changes that occurred as a result of a brief training programme of nine weeks which concentrated on aerobic development and then proceeded to stress the anaerobic metabolic pathways. In the last two weeks of the programme, when exercise loads were of the order of 90 per cent and 100 per cent of maximum, interrupted by long periods of inactive rests (four minutes), both the phosphagen and glycolytic energy pathways would be stressed maximally. It was found that the mental effort and motivation required by the subjects to sustain training at this intensity was considerable.

In particular, attention in this study was focused on the changes that occurred in fibre cross-sectional area as a result of the training regimen. It was interesting to observe that, despite initial training being aerobic in nature, there was no significant change in cross-sec- 
tional area of Type I fibres. However, the increase that occurred in the cross-sectional area of Type II fibres was substantial, of the order of 82 per cent. No distinction was made between Type IIa and Type IIb fibres. The results of previous studies which have concentrated on the effects of short term high intensity training have shown that, in addition to increased Type II fibre area, increases can also be observed in maximal muscle tension and an increase in enzymes hexokinase and citrate synthetase ${ }^{25,26}$. However, Polgar and Johnson suggested that fibre size is relatively unimportant and that the physiological roles of muscles are a function of enzyme adaptation ${ }^{27}$.

\section{Conclusion}

If the sport of slalom canoeing demands a major contribution from anaerobic glycolysis, then it is essential that slalomists incorporate training regimens which stress that metabolic pathway. One such routine has been suggested in this study and its effects in terms of muscle fibre development have been reported. It would appear that since the action of high intensity paddling enhances Type II muscle fibre development, then slalom competitors who are endowed with a large proportion of these fibres may have an advantage in this sport.

\section{Acknowledgements}

This study was funded by the Research Committee of the Gwynedd Health Authority. The authors wish to express their thanks to Mr R.H.T. Oliver, consultant surgeon and his colleague, Dr T. White at Ysbyty Gwynedd for obtaining samples by needle biopsy. Thanks are also extended to Professor Crisp who allowed the use of the biochemical laboratory and to Dr G. Walker who guided the biochemical analysis, both of University College Bangor.

\section{References}

1 Gollnick, P.D., Piehl, K. and Saltin, B. Selective glycogen depletion pattern in human muscle fibers after exercise of varying intensity and at varying pedalling rates J Physiol 1974, 241, 45-47

2 Secher, N.H. and Nygaard-Jensen, E. Glycogen depletion patterns in Type I,IIA and IIb muscle fibres during maximal voluntary static and dynamic exercise Acta Physiol Scand Suppl 1976, 440, 287

3 Secher, N.H., Rorsgaard, S. and Secher, O. Contralateral influence on recruitment of type I muscle fibres during maximal voluntary extension of legs Acta Physiol Scand 1976, 96, 20A-21B

4 Thorstensson, A., Hutlen, B., Von Dobeln, W. and Karlsson, J. Effect of strength training on enzyme activity and fibre characteristics in human skeletal muscle Acta Physiol Scand 1976, 96, 392-398

5 McGrail, J.C., Bonen, A. and Belcastro, A.N. Lactic acid metabolism during exercise Res papers in Phys Ed 1977, 3(3), 4-9
6 Bevegard, S., Freychuss, J. and Strandell, T. Circulatory adaptations to arm and leg exercise in supine and sitting positions J Appl Physiol 1966, 21, 37-46

7 Baker, S.J. Post competition lactate levels in canoe slalomists Br J Sports Med 1982, 16(2), 112

8 Tesch, P.A. Physiological characteristics of elite Kayak paddlers Can J Appl Sports Sci 1983, 8(2), 87-91

9 Baker, S.J. 'A study of the behavioural profiles of elite slalom canoeists' PhD thesis, University College of North Wales, 1984

10 Edwards, R.H.T., Jones, D.A., Maunder, C. and Batra, G.J. Needle biopsy for medical chemistry Lancet 1975, 3, 29

11 Dubowitz, V. and Brooke, M.H. 'Muscle biopsy: A modern approach' Saunder Co Ltd, London, 1973

12 Stotgaard, G., Houston, M.E., Nygaard, E. and Saltin, B. Subgrouping of fast twitch fibres in skeletal muscle of man - a critical appraisal Histochem 1978, 58, 79-87

13 Karlsson, J., Sjödin, B., Tesch, P. and Larsson, L. The significance of muscle fibre composition to human performance capacity Scand J Rehab Med 1978, 10(6), 50-61

14 Humphrey, K.E. 'An investigation of the fibre composition in the deltoid muscle of elite British slalom kayak competitors' BA thesis, University College of North Wales, 1982

15 Tesch, P., Piehl, K., Wilson, G. and Karlsson, J. Physiologial investigation of Swedish elite canoe competitors Med Sci in Sport 1976, 8(4), 214-218

16 Ivy, J.L., Withers, R.T., Van-Handel, P.J., Elger, D.H. and Costill, D.L. Muscle respiratory capacity and fibre type as determinants of the lactate threshold $J$ Appl Physiol 1980, 49(3), 523-527

17 Mayes, R., Hardman, A.E. and Williams, C. The influence of training on endurance and blood lactate concentrations during submaximal exercise Brit $J$ Sports Med 1987, 21(3), 119-124

18 Essen, B., Jansson, E., Henricksson, E., Taylor, A.W. and Saltin, B. Metabolic characteristics of fibre types in human skeletal muscle Acta Physiol Scand 1975, 95, 153-165

19 Thorstensson, A., Sjodin, B., Tesch, P. and Karlsson, J. Actomyosin ATPase, myokinase, CPK and LDH in human fast and slow twitch fibres Acta Physiol Scand $1977,99,225-229$

20 Bar-Or, O., Dotan, R., Inbar, A., Rothstein, J., Karlsson, J. and Tesch, P. Anaerobic capacity and muscle fibre type distribution in man Int J Sports Med $1980,1,82-85$

21 Newman, E.V., Dill, D.B., Edwards, H.T. and Webster, F.A. The rate of lactic acid removal in exercise Am J Physiol 1936, 118(3), 457-462

22 Brooks, G.A., Brauner, K.E. and Cassens, R.G. Glycogen synthesis and metabolism of lactic acid after exercise Am J Physiol 1973, 224, 1162

23 Koutedakis, Y. and Sharp, N.C.C. Lactic acid removal after rowing Br J Sports Med 1985, 19(4), 199-202

24 Karvonen, J., Rauhala, E., Chwalbinska-Moneta, J. and Hänninen, $\mathrm{O}$. Metabolic changes caused by slalom training Scand J Sports Sci 1985, 7(2), 51-53

25 Staudte, W.H., Exner, V.G. and Pette, D. Effects of short term high intensity training on some contractile and metabolic characteristics of fast and slow muscles of the rat Pflügers Arch 1973, 344, 159-168

26 Saubert, C.W., Armstrong, R.B., Shepherd, R.E. and Gollnick, P.D. Anaerobic enzyme adaptations to sprint training in rats Pflüger Arch 1973, 341, 305-312 